\title{
Numerical Prediction and Comparison of Finite Element and Finite Difference Methods of Flood Routing
}

\author{
${ }^{1}$ Muhammad Mushtaque Rajput, ${ }^{2}$ Syed Mushtaque Ahmed Shah \\ ${ }^{1,2}$ Mechanical Engineering Department Balochistan University of Engineering \& Technology, Khuzdar, \\ Pakistan
}

\begin{abstract}
The problems of flood wave propagation in bodies of waters caused by intense rains or floods represent a great challenge in mathematical modeling processes. With the progress of digital computers, the mathematical models become the great option in the analysis of this class problem. In this research, a finite element model developed for the prediction of flood routing in rivers. The developed model has been validated through comparing against other numerical model results and compared with observed data of a river reach. The developed model is capable of simulating the food hydrograph at any distance; the attenuation has been predicted accurately through the model. The results shows that the peak flow attenuation is non-linear trend in shape, which describes that at the initial stage, the attenuation of peak flow is greater as compared to the attenuation at the succeeding section/location at the downstream. However, this attenuation is going to be linear as the peak flow is moving towards the downstream end. The values for successive peak flow attenuation have also been computed which clearly demonstratethat this peak flow attenuation (PFA)has been diminished and remain negligible at some location on the downstream. The developed model is also capable of computing lag time which is necessary for the flood routing.
\end{abstract}

Keywords: Flood routing; Finite element; Finite difference methods.

\section{Introduction}

Rivers, estuaries ad other waterways have long served many important uses for mankind and, at the same time; have been subjected to stresses by diverse human activities. Such uses and stresses have made it necessary for hydrologists and hydraulicians to understand the complicated behavior of water movement and interaction with its environment by means of computer simulation commonly known as mathematical modeling. The aim of a flood model is to simulate on a real time scale the rise and fall of floodwater. With the help of model efficient planning of flood plain occupation becomes possible [1]. Once a system has been modeled it is an easy exercise to forecast the consequences of such a system [6].

Literature shows that the numerical model, using finite element method, is accurate and efficient [5]. Therefore, in this research, finite element method will be used for the prediction of flood routing in open channels.

Governing Equations:

The continuity equation

The momentum equation

$$
\frac{\partial A}{\partial t}+\frac{\partial(Q)}{\partial x}=0
$$

$$
\left.\frac{\partial Q}{\partial t}+\frac{\partial\left(Q^{2} / A\right)}{\partial x}+g A \mid \frac{\partial y}{\partial x}+S_{f}-S_{o}\right\rfloor=0
$$

The Diffusion WaveModel simplified form of the Saint-Venant Equationscould give a good accuracy in the results for flood routingin the rivers [4].The governing equation for the diffusive wave model is described as follows:

$$
\frac{\partial Q}{\partial t}=-c \frac{\partial Q}{\partial x}+D \frac{\partial^{2} Q}{\partial x^{2}}
$$

Where $c=\frac{d Q}{d A}$ is wavecelerity and $D=\frac{Q_{0}}{2 B S_{0}}$ is diffusion coefficient.

Flood wave has its own special features and requires special techniques for exploring these features. For instance,the rise and fall of a flood occurs much more slowly than many other types of unsteady flow changes, and thus some of the terms in the Saint-Venant equations [7] may be neglected to obtain simplified useful model in many cases. Consequently two simplified forms of the Saint-Venant equations are available. One of them is Kinematic Wave Equationthat obtained by neglecting the diffusive term of the Diffusion wave model [7]. 


$$
\frac{\partial Q}{\partial t}+c \frac{\partial Q}{\partial x}=0
$$

Where $c=\frac{d Q}{d A}$ is the kinematic wave speed. For a wide channel $\mathrm{c}$ is equal to $1.5 \mathrm{U}$ when the Chezyformula is used and 1.67 when the Manning's formula is used.

\section{a) Development of Finite Element Model}

Thekinematic wave equation (4) can only be solved analytically when the celerity c is constant. However, $\mathrm{c}$ is not constant; the equation becomes non-linear and has to be solved numerically. In this study, governing equation (4) has been solved using the predictor-corrector Taylor-Galerkin Finite Element scheme. The Taylor-Galerkin schemeoriginally introduced by [2].[3]Presentedthis method for Navier-Stokes equation only. The Taylor-Galerkin scheme proved to be effective and efficient and has been employed to establish a finite element model for flood routing in order to compute time lag between two peaks and peak attenuation between two hydrograph i.e. at inlet and outlet in the downstream.

\section{b) Two-step Predictor-Corrector outlet Finite Element Scheme}

In the proposed finite element model, two-step Lax-Wendroff predictor-corrector technique has been adopted: at step one the discharge $\mathrm{Q}$ at half time step $(\mathrm{n}+1 / 2)$ level is predicted then using this information, correct the second-order accurate $\mathrm{Q}$ at step two i.e. $(\mathrm{n}+1)$ full time level.

Step1: Predict discharge $\mathrm{Q}$ at half time step $(\mathrm{n}+1 / 2)$ level using following equation.

$$
Q^{n+\frac{1}{2}}=Q^{n}+\frac{1}{2} \Delta t[-f n]^{n}
$$

Step2: using the above information, correct the second order accurate Qat $(\mathrm{n}+1)$ full time level using the equation:

$$
Q^{n+1}=Q^{n}+\Delta t[-f n]^{n+\frac{1}{2}}
$$

The Taylor-Galerkin method originally proposed in[2] to solve the time-dependent convective transport problems to drive highly accurate time-steppingscheme for solving transient as well as steady flow problems. [2] and [3] shows that the above described scheme gave more accurate and stable results if compared with both finite difference method (FDM) and Euler-Galerkin finite element method.

Therefore, in this paper the proposed finite scheme is based on two-step predictor-corrector TaylorGalerkin scheme.

\section{c) Fully Discrete System with approximate functions}

Before using approximate function for the system of equation (4),the weighted residual technique is utilized that can be read as:

$$
\int_{\Omega} \omega R d \Omega=\int_{\Omega} \omega\left(f-f_{c} \mathrm{~d} \Omega=0\right.
$$

In the weak form, the full-discrete system using weighed residual technique will be:

$$
\frac{2}{\Delta t} \int_{\Omega} \omega\left({ }_{Q}^{n+1}-{ }_{Q}^{n}\right) \mathrm{d} \Omega=\left[-\int_{\Omega} \omega\left(C \frac{\partial Q}{\partial x}\right) \mathrm{d} \Omega\right]^{n}
$$

The finite element spatial approximation is applied to the above equation by Galerkinmethod, hence the finite element Galerkin approximation for the flood routing value will be as follows:

$$
\begin{aligned}
\mathrm{Q}(\mathrm{x}, \mathrm{t})=\sum_{j=1}^{3} \varphi_{j}(x) Q_{j}(t) \frac{2}{\Delta t} \int_{\Omega} \varphi_{i} \varphi_{j}\left(i^{n+1 / 2}-{ }^{n}\right) \mathrm{d} \Omega & \\
= & {\left[-\int_{\Omega} \varphi_{i} \varphi_{l} C_{l} \varphi_{j} d T Q_{j}+\int_{\Omega} \frac{\partial \varphi_{i}}{\partial x} \varphi_{l} C_{l} \varphi_{j} \mathrm{~d} \Omega Q_{j}\right]^{n} }
\end{aligned}
$$

After mathematical manipulation, the equation for computing the discharge/flood value at half time step will be: 


$$
\begin{aligned}
& \frac{2}{\Delta t} \int_{\Omega} \varphi_{i} \varphi_{j}\left({ }_{Q}^{n+1 / 2}-{ }^{n}\right) \mathrm{d} \Omega \\
= & {\left[\int_{\Omega} \frac{\partial \varphi_{i}}{\partial x} \varphi_{l} C_{l} \varphi_{j} \mathrm{~d} \Omega Q_{j}\right]^{n} }
\end{aligned}
$$

The fully discrete form of explicit Taylor-Galerkin predictor-corrector scheme will be written as follows:

Step1:

$$
\frac{2}{\Delta t} M\left(Q_{j}{ }^{n+\frac{1}{2}}-Q_{j}{ }^{n}\right)=-C N(W) Q_{j}{ }^{n}
$$

Step2:

$$
\frac{1}{\Delta t} M\left(Q_{j}{ }^{n+1}-Q_{j}{ }^{n}\right)=-C N(W) Q_{j}{ }^{n+\frac{1}{2}}
$$

The computer code has been made using Matlab for the solution of above equations (9) and (10).

\section{Results And Discussions}

In this section the developed model has been compared with the computed results of finite difference method, in which a mathematical inflow hydrograph is shown in Figure.1 for flood routing in Hypothetical River.

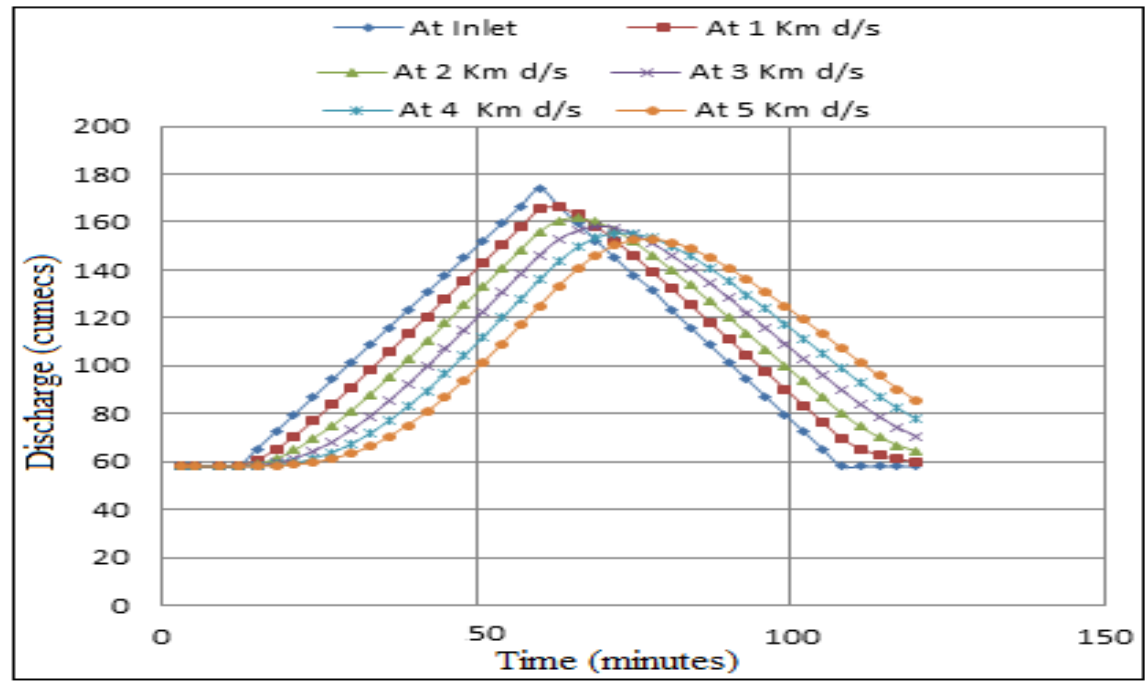

Fig.1. Computed Hydrographs at different location on the down stream

The figure. 1 shows that the peak flow of attenuation is increased with distance. The values for the peak flow attenuation at various distances are calculated and tabulated in Table 1.

Figure. 2 shows that the peak flow attenuation is a non-linear trend in shape, which describes that at the initial stage, the attenuation of peak flow is greater as compared to the attenuation at the succeeding section/location at the downstream. However, this attenuation is going to be linear as the peak flow is moving towards the downstream end. The values for the successive peak flow attenuation have also been computed which clearly demonstrate that this peak flow attenuation has been diminished and remain negligible at some location on the downstream.

Table.4 shows that the author's computed values for flood routing and those ofVICAIRE (Virtual Campus In hydrology and water Resources management)are matching with each other. The close agreement between two numerical methods showed the suitable applicability of the finite element scheme for flood hydrographs various distances in downstream. However, the maximum errors have been noted is about $0.2 \%$ (see table. 3) 


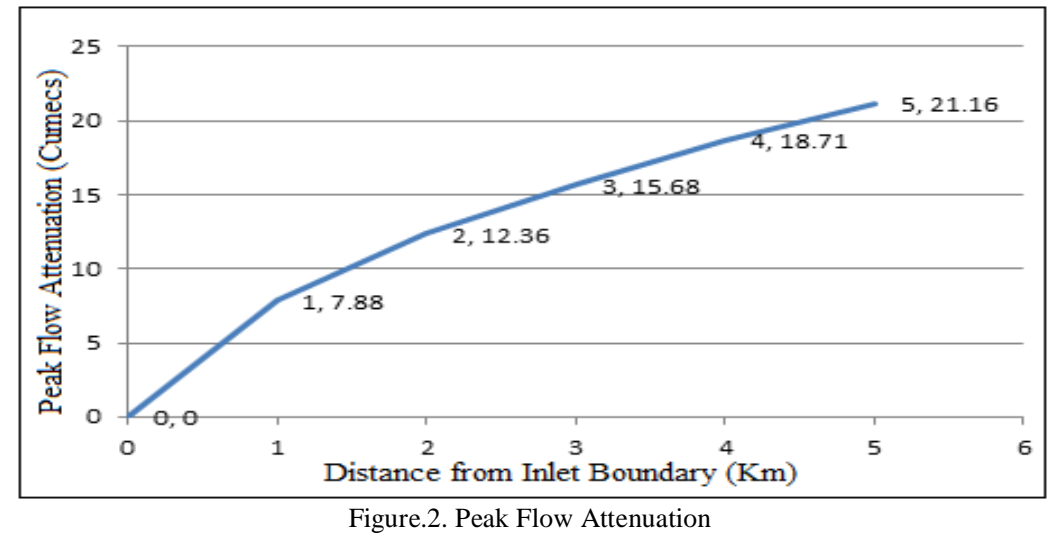

TABLE 1TABLE. 3

PEAK FLOW ATTENUATION AT VARIOUS DIST ANCESMAXIMUM DIFFERENCE ERROR

\begin{tabular}{|c|c|c|c|}
\hline \hline $\begin{array}{c}\text { Distance } \\
\text { from Inlet } \\
(\mathrm{km})\end{array}$ & $\begin{array}{c}\text { Peak Flow } \\
\text { at various } \\
\text { distances } \\
\text { (cumecs) }\end{array}$ & $\begin{array}{c}\text { Peak } \\
\text { Flow } \\
\text { Attenuati } \\
\text { on } \\
\text { (cumecs) }\end{array}$ & $\begin{array}{c}\text { Successive } \\
\text { Peak Flow } \\
\text { Attenuatio } \\
\text { (cumecs) }\end{array}$ \\
\hline 0 & 174 & $\ldots \ldots \ldots$ & $\ldots \ldots \ldots$ \\
\hline 1 & 166.12 & 07.88 & \\
\hline 2 & 161.64 & 12.36 & 4.48 \\
\hline 3 & 158.32 & 15.68 & 3.32 \\
\hline 4 & 155.29 & 18.71 & 3.03 \\
\hline 5 & 152.84 & 21.16 & 2.45 \\
\hline
\end{tabular}

\begin{tabular}{|c|c|c|c|}
\hline \multirow{2}{*}{$\begin{array}{l}\text { Distance } \\
\text { from Inlet } \\
(\mathrm{km})\end{array}$} & \multicolumn{2}{|c|}{$\begin{array}{c}\text { Numerical Predictions of } \\
\text { Flood Discharge }\end{array}$} & \multirow{2}{*}{$\begin{array}{c}\text { Maximum } \\
\text { Absolute } \\
\text { Relative } \\
\text { Difference } \\
(\%)\end{array}$} \\
\hline & Author (FEM) & $\begin{array}{l}\text { Vicaire } \\
\text { (FDM) }\end{array}$ & \\
\hline 1 & 163.12 & 162.99 & 0.08 \\
\hline 2 & 156.08 & 155.99 & 0.06 \\
\hline 3 & 156.42 & 156.73 & 0.20 \\
\hline 4 & 76.97 & 76.87 & 0.13 \\
\hline 5 & 117.2 & 117.09 & 0.09 \\
\hline
\end{tabular}

III. Conclusion

The predicted discharges using the developed two-step Predictor-Corrector Finite Element Model are coincidingthe numerical resultsof VICAIRE, who has used the Finite Difference Method. Hence the developed model is accurate and efficient. The developed model is capable of simulating the flood hydrograph at any distance as well as time lag. The attenuation has been predicted accurately by the model. The observed peak flow attenuation is 21.25 cumecs and lag time is 18 minutes for the reach of 5 kilometerdistance. The same parameters for any required distance can also be computed.To achieve suitable solution, a uniform flow condition as initial condition be prescribed.The developed model is a goodtool to determine water surface profile of a peak flood discharges.

TABLE. 4

COMPARISON OF AUTHORS (FEM) PREDICTED RESULTS AGAINST VICAIRE(FDM)

\begin{tabular}{|c|c|c|c|c|c|c|c|c|c|c|c|}
\hline \multirow{2}{*}{$\begin{array}{l}\text { Time } \\
\text { (min) }\end{array}$} & \multirow{2}{*}{$\begin{array}{l}Q \text { at } \\
\text { Inlet }\end{array}$} & \multicolumn{2}{|c|}{$1 \mathrm{Km}$} & \multicolumn{2}{|l|}{$2 \mathrm{~km}$} & \multicolumn{2}{|l|}{$3 \mathrm{~km}$} & \multicolumn{2}{|c|}{$4 \mathrm{~km}$} & \multicolumn{2}{|r|}{$5 \mathrm{~km}$} \\
\hline & & Author & VICAIR. & Author & VICAIRE & Author & VTCATRE & Author & VTCAIRE & Author & YTCAIRE \\
\hline 3 & 58 & 58 & 58 & 58 & 58 & 58 & 58 & 58 & 38 & 58 & 58 \\
\hline 15 & 65.25 & 60.72 & 60,63 & 59.03 & 58.94 & 38.43 & 38,34 & 58.21 & 58.12 & 58.06 & 38.04 \\
\hline 21 & 79.75 & 70.67 & 70.59 & 64.72 & 64.63 & 61,36 & 61.27 & 59.45 & 59.54 & 58.75 & 58.7 \\
\hline 27 & 94.25 & 83.82 & 83.74 & 74.9 & 74.8 & 68.26 & 68.17 & 63.87 & 63.78 & 61.19 & 61.12 \\
\hline 45 & 137.75 & 128.09 & 127.98 & 117,76 & 117.66 & 107.16 & 107.06 & 96.75 & 96.65 & 87.17 & 87.07 \\
\hline 51 & 152.25 & 143.11 & 1.42 .91 & 133.12 & 133.02 & 122.72 & 122.62 & 111.99 & 111.93 & 101.46 & 101,36 \\
\hline 57 & 166.75 & 157.9 & 157.8 & 148.45 & 148.36 & 138.47 & 138.37 & 127.96 & 127.89 & 117.2 & 117.09 \\
\hline 63 & 166.75 & 166.12 & 165.92 & 160.59 & 160.51 & 152.76 & 152,67 & 143.43 & 143.38 & 133.28 & 133.17 \\
\hline 69 & 152.25 & 158.21 & 158.12 & 160.09 & 160.4 & 158.32 & 158.23 & 153.45 & 153.36 & 146.24 & 146.15 \\
\hline 99 & 79.75 & 90.39 & 90.32 & 100.17 & 100.1 & 109.26 & 109.17 & 117.55 & 117.5 & 125.06 & 124.98 \\
\hline 105 & 65.25 & 76.54 & 76.49 & 86.82 & 86.70 & 96.32 & 96.28 & 105.16 & 105.12 & 113.35 & 113,28 \\
\hline 111 & 58 & 65.43 & 65.38 & 74,62 & 74,57 & 83.99 & 83.92 & 9298 & 92.93 & 101.49 & 101,45 \\
\hline 117 & 58 & 61.04 & 61 & 66.53 & 66.78 & 74.21 & 74.15 & 82.25 & 82.2 & 90,36 & 90.36 \\
\hline 120 & 58 & 59.94 & 59.92 & 64.31 & 64,27 & 70.51 & 70,46 & 77.75 & 77.7 & 85.45 & 85.4 \\
\hline
\end{tabular}




\section{References}

[1] Clifford, D. and Weinz, W. W. (1978),"Suit of Mathemitical Flood Plain Models”, Jour. Hydraulic Division, Amer. Soc. Civil Engrs. Vol 104, No.HY3.

[2] Donea, J. (1984)," A Taylor Galerkin method for Convective Transport Proble|, Journal of Fluid Mechanics, Vol.5, No. 4, pp.10 1119

[3] Hawken, D.M., Townsend, P. and Webster, M.F.(1991)," Numerical Simulation of Viscous Flows in Channels With a Step", Jour. Of Computers Fluids, Vol.20, No.1, pp.59-75

[4] obson, H. E. (1989), "User's Manual for a Flow Model Based on the Diffusion Analogy”, U.S. Geological Survey,ResftonVirgina, 1989. - 56p.

[5] Qureshi, A. L. and Baloch, A (2004a). "Finite Element Simulation for the Bed Aggradation due to sendiment overloading in the Alluvial Channels", $3^{\text {rd }}$ International Bhurbhan Conference on Applied Science and Technology (IBCAST), organized by National Center of Physics, Quaid-Azam University, Islamabad.

[6] C.G. Aguirre, A. Madani”, Deterministic finite element solutionof unsteady flow and transport through porous media: Model verification", Canadian bio systems engineering, Volume 49, 2007.

[7] Saint-Venant, Barre, "Theory of unsteady water flow with application to river floods and to propagation of tides in river channels. Computes Rendus, volume 73. 1973.

[8] A. D. Koussis1, K. Mazi1, "Reverse flood routing with the inverted Muskingum storage routing scheme Published by Copernicus Publications on behalf of the European Geosciences Union", doi:10.5194/nhess-January 2012

[9] P. Bhambri, "Streamline based black-oil simulation and its application to waterflooding, Int. J. of Oil, Gas and Coal Technology, Vol.5, No.2/3, pp.267-298, 2012 